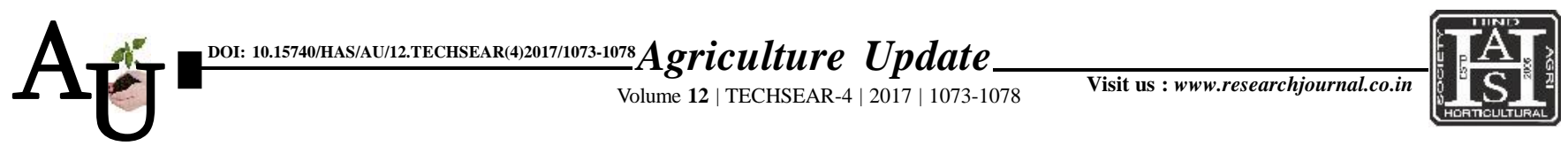

\title{
Research Article: Partial least square structural equation modeling in knowledge management orientation: A role of marketing capability in a model to firm performance of agri-input retailer
}

\author{
Article Chronicle : \\ Received : \\ 14.07.2017; \\ Accepted : \\ 29.07.2017
}

KEY WoRDS :

Knowledge

management

orientation, Firm

performance,

Marketing capability,

Partial least square

model
SUMMARY : The increasing importance of knowledge in the modern and globalized organization had initiated a need to focus on managing knowledge as an organizational and competitive asset. Some of agri-input retailers attended training programmes to enhance their knowledge. The study was deemed essential to study the relationship between the Knowledge Management Orientation, Marketing Capabilities and Firm Performance. Accordingly, the study was undertaken to analyze the Knowledge Management Orientation and performance of agri-input retailers in western zone of Tamil Nadu. The population for this study comprised of trained and untrained agri-input retailers in the Western zone of Tamil Nadu comprising Coimbatore and Erode districts. From the population of agri- Input retailers, 120 trained and 120 untrained retailers were selected by convenience sampling method. Hence, the total sample size was 240 agri-input retailers drawn from the population of study. The component based Structural Equation Method was used to analyse the relationship between KMO, MC and FMP. In the indirect relationship between the $\mathrm{KMO}, \mathrm{MC}$ and FMP, it was concluded that there was positive influence of KMO on MC which in turn had positive relationship with Firm Performance. The partial mediation of Marketing Capabilities was confirmed. Among the Marketing Capabilities, the influence of Brand Management Capability on Customer Performance was insignificant.

How to cite this article : Malarkodi, M., Uma, K., Indumathi, V. M. and Divya, K. (2017). Partial least square structural equation modeling in knowledge management orientation: A role of marketing capability in a model to firm performance of agri-input retailer. Agric. Update, 12 (TECHSEAR-4): 1073-1078; DOI: 10.15740/HAS/ AU/12.TECHSEAR (4)2017/1073-1078.
Author for correspondence :

\section{MALARKODI}

Department of Social Sciences, ACR and RI, Tamil Nadu Agricultural University, KILLIKULAM (T. N.) INDIA

See end of the article for authors' affiliations 